\title{
Surgical Repair of Congenital Diaphragmatic Hernia During Extracorporeal Membrane Oxygenation: Hemorrhagic Complications and the Effect of Tranexamic Acid
}

\author{
By F.H.J. van der Staak, A.F.J. de Haan, W.B. Geven, and C. Festen \\ Nijmegen, The Netherlands
}

\begin{abstract}
- Extracorporeal membrane oxygenation (ECMO) was incorporated in a strategy of delayed repair of congenital diaphragmatic hernia ( $\mathrm{CDH}$ ) and was used for preoperative stabilization in patients who were unresponsive to maximal conventional treatment. If ECMO was required for preoperative stabilization the diaphragmatic defect was repaired while the patient was on ECMO. In the early experience with this approach all patients suffered from bleeding complications. Therefore, we adopted the use of antifibrinolytic therapy with tranexamic acid (TEA) during and immediately after $\mathrm{CDH}$ repair on ECMO. The efficacy of TEA was studied in an unblinded study using historical controls by comparing the postoperative blood loss and the transfusion requirements of red blood cells (RBC) in patient groups treated without $(n=9)$ and with TEA ( $n=10$ ). Patients who received TEA had significantly less bleeding at the surgical site than patients not receiving TEA $(57 v 390 \mathrm{~mL}, P=.005)$ and had significantly lower RBC transfusion requirements than patients not receiving TEA (1.13 v $2.95 \mathrm{~mL} / \mathrm{kg} / \mathrm{h}, P=.03)$. In the very first two patients of the TEA group we encountered fairly severe thrombotic complications. TEA may have contributed to those complications. Based on the authors' experience they conclude: (1) TEA is effective in reducing postoperative blood loss, hemorrhagic complications, and RBC transfusion requirements associated with $\mathrm{CDH}$ repair on ECMO. (2) TEA may be responsible for thrombotic complications. (3) The appropriate, empirically established, dosage and administration patterns of TEA for $\mathrm{CDH}$ repair during ECMO seem to be one bolus of $4 \mathrm{mg} / \mathrm{kg}$ TEA intravenously 30 minutes before the anticipated $\mathrm{CDH}$ repair and a continuous infusion of $1 \mathrm{mg} / \mathrm{kg} / \mathrm{h}$ TEA during the 24 hours after $\mathrm{CDH}$ repair.

Copyright $₫ 1997$ by W.B. Saunders Company
\end{abstract}

INDEX WORDS: Congenital diaphragmatic hernia, extracorporeal membrane oxygenation, bleeding complications, tranexamic acid.

$\mathbf{S}$ INCE EXTRACORPOREAL membrane oxygenation (ECMO) became available in our institution in January 1991, ECMO was incorporated in a protocol of preoperative stabilization and delayed repair for congenital diaphragmatic hernia (CDH). ${ }^{1}$ If FCMO was necessary for preoperative stabilization, surgical repair of the

From the Departments of Pediatric Surgery; Medical Informatics, Epidemiology and Statistics; and Neonatology; Faculty of Medical Sciences, Iniversity of Nijmegen, The Netherlands.

Address reprint requests to F.H.J. van der Staak, MD, Department of Pediatric Surgery, University Hospital Nijmegen, PO Box 9101, 6500 HB Nimegen, The Netherlands.

Copyright (C) 1997 by W.B. Saunders Company

$0022-3468 / 97 / 3204-0015 \$ 03.00 / 0$ diaphragmatic defect was performed while the patient was on ECMO at the end of the ECMO-run. ${ }^{2}$

In the early experiences with this approach significant postoperative bleeding complications were encountered at the surgical site. ${ }^{2}$ In all first six patients--who form part of this study-bleeding complications occurred, requiring 455 to $1215 \mathrm{~mL}$ red blood cells (RBC; mean, $850 \mathrm{~mL}$ ). Four of the six patients were forcefully weaned from ECMO because of the hemorrhage, and three of these four died of recurrent pulmonary hypertension.

Wilson et $\mathrm{al}^{\mathrm{\beta}}$ were the first who described the effect of an antifibrinolytic agent on hemorrhagic complications during ECMO. They administered $\epsilon$-aminocaproic acid (EACA) to 42 patients who were considered to be at high risk for bleeding complications (such as anticipated surgical procedures, preexisting intracranial hemorrhage $[\mathrm{ICH}]$ or profound hypoxia), starting just before or after cannulation until decannulation. Compared with 68 patients not receiving EACA, the patients who received EACA had significantly less bleeding while on ECMO and required fewer blood transfusions. This difference was most significant in the congenital diaphragmatic hernia and cardiac subgroups. The incidence of ICH in the neonatal subgroup was also significantly reduced in the EACA group. These investigators advocated the use of EACA for all patients who were thought to be at risk for hemorrhagic complications on ECMO.

Therefore we adopted the use of an antifibrinolytic agent as advocated by Wilson et al. ${ }^{3}$ Since January 1993 we administered tranexamic acid (TEA) during and after $\mathrm{CDH}$-repair on ECMO. In this report our experience with hemorrhagic and thrombotic complications in $\mathrm{CDH}$ repair during ECMO is presented, and the effect of TEA is evaluated.

\section{MATERIALS AND METHODS}

Since January 1991, 20 high-risk CDH patients needed ECMO support for preoperative stabilization in our institution. In all patients veno-arterial ECMO was used as described by Bartlett et al. ${ }^{4}$ During the ECMO run heparin was titrated to maintain the activated clotting time (ACT) at levels of 200 to 220 seconds with ECMO-flow rates higher than $250 \mathrm{~mL} / \mathrm{min}$. ACTs were monitored at the bedside using the Hemochron (International Technidyne Corp, Edison, NJ). At lower $\mathrm{ECMO}$ flow rates higher ACT levels were maintained (for example, ACT levels of 240 to 250 seconds at ECMO flows of 50 to 200 $\mathrm{mL} / \mathrm{min}$ ). ACT goals were not different in any one of the groups. Thrombocytes were administered to maintain their count above the level of $80 \times 10^{9} / \mathrm{L}$ pre-CDH repair and above $100 \times 10^{9} / \mathrm{L}$ during and after $\mathrm{CDH}$ repair. The $\mathrm{ACT}$ was monitored every hour, and the platelet 
counts were determined every 8 hours. RBCs were routinely transfused to maintain the hematocrit greater than $40 \%$ and the hemoglobin concentration above $8.0 \mathrm{mmol} / \mathrm{L}$. CDH repair was performed at the end of the ECMO run if the patient was weanable from ECMO and the ECMO flow could be decreased to $50 \mathrm{~mL} / \mathrm{min}$.

During surgery we avoided major dissections and incidental procedures, and we used running sutures to close the defect. If the defect was too large for primary closure a prosthetic patch (Gore-tex soft tissue patch) was used. Fibrin glue was spread on the suture line at the end of the repair. During and directly after surgical repair we tried to preclude major bleeding complications by running high ECMO flows, which allow relatively low ACTs (aim, 180 to 200 seconds). This strategy was the same during the whole study period. The surgical procedure has been founded on a long-lasting experience, did not undergo a fundamental change, and was performed by the most experienced surgeon in the first group and by several surgeons in the second group.

Nineteen patients underwent elective repair while on ECMO; in one patient ECMO was stopped because of a severe intracranial hemorrhage at day 1 of ECMO, and she died. The patients were divided into 2 groups. Group 1 consisted of 9 patients who underwent repair without the use of TEA (1991 to 1992) and group 2 contained 10 patients who received TEA (1993 to 1995 ).

Except for the addition of TEA the ECMO protocol was identical for both groups. TEA administration happened in different ways. In the first patient TEA was given intermittently by intravenous infusion, $15 \mathrm{mg} / \mathrm{kg}$ every 8 hours, during the first 48 postoperative hours. In all other patients TEA was administered by an intravenous loading bolus just before surgery $(10 \mathrm{mg} / \mathrm{kg}$ in patients 2 and 3 , and $4 \mathrm{mg} / \mathrm{kg}$ in the ensuing patients), followed by a continuous intravenous infusion of $2 \mathrm{mg} / \mathrm{kg} / \mathrm{h}$ TEA over 48 hours in the second patient and of $1 \mathrm{mg} / \mathrm{kg} / \mathrm{h}$ TEA over 24 hours in the third and ensuing patients.

For all patients the total blood loss was recorded. Total blood loss was defined as the peroperative blood loss from the surgical site and the postoperative bleeding from the chest tube. The blood losses were calculated in reference to the body weight and the postoperative ECMO time (ie milliliters blood per $\mathrm{kg}$ of body weight and per postoperative ECMO hour). The transfusion requirements of red blood cells were assessed for the whole ECMO run as well as in relation to the weight of the patients, the duration of the ECMO run, and the moment of CDH repair. The incidence of reexploration for bleeding and the thrombotic complications were noted in addition to the incidence of forced discontinuation of ECMO because of bleeding. For statistical analysis of the differences in both groups the two-sided Wilcoxon's rank sum test and the two-sided Fisher's Exact test were used. $P$ values of less than .05 were considered significant.

\section{RESULTS}

Both groups were comparable with respect to birthweight, age at institution of ECMO, side of the defect, patch repair, and the time of $\mathrm{CDH}$ repair during ECMO (Table 1). Only for the duration of the ECMO run was there a significant difference between both groups. Seven of the nine group 1 patients $(78 \%)$ and 9 of the 10 group 2 patients $(90 \%)$ had a left-sided defect. Patch repair was accomplished in 16 patients: 8 from group 1 (89\%) and 8 from group $2(80 \%)$.

Hemorrhagic complications led to a forced discontinuation of ECMO support in five of the nine patients of group 1 -in one patient even after heparinization had been stopped. Four of the five patients who were removed earlier from ECMO because of bleeding died of rebound pulmonary hypertension. One patient in each group requircd an abdominal reexploration becausc of hemorrhage. There were four patients with thrombotic complications (two in cach group). The thrombotic patient complications consisted of an upper caval vein thrombosis centered around a central venous line placed immediately after ECMO, at the time of decannulation, via the internal jugular vein. These complications seemed to be more severe in the first two patients of group 2. A chylothorax developed in both patients, which lasted for several weeks despite special MCT formulas and even complete discontinuation of entcral fccding. In onc patient of group 1 the obstructed venous return may have led to a hydrocephalus. In addition, in two cases of group 2 there were clots in the circuit. The survival rate for group $2(100 \%)$ was significantly higher than for group 1 (56\%) (Fisher's Exact test, $P<.05$ ).

The median total intra- and postoperative blood loss was significantly different: $390 \mathrm{~mL}$ in group 1 versus 57 $\mathrm{mL}$ in group 2 (Wilcoxon's rank sum, $P=.005$, Fig $1 \mathrm{~A}$ ), The median intra- and postoperative blood loss in reference to the postoperative ECMO time and the body weight was significantly less in group $2: 2.26 \mathrm{~mL} / \mathrm{kg} / \mathrm{h}$ in group 1 versus $0.49 \mathrm{~mL} / \mathrm{kg} / \mathrm{h}$ in group 2 (Wilcoxon's rank sum, $P=.02$, Fig 1B).

The median transfusion requirement of $\mathrm{RBC}$ during an ECMO run in group 1 was significantly more than in group 2: $838 \mathrm{~mL}$ versus $442 \mathrm{~mL}$ (Wilcoxon's rank sum, $P=.003$, Fig 2A). In respect to the preoperative transfusion requirement of $\mathrm{RBC}$ there is no difference between both groups: median amount of $0.83 \mathrm{~mL} / \mathrm{kg} / \mathrm{h}$ (group 1) versus $0.96 \mathrm{~mL} / \mathrm{kg} / \mathrm{h}$ (group 2, Wilcoxon's rank sum, $P=.3$ ). The difference in intra- and postoperative requirements of RBC between both groups is statistically significant: median of $2.96 \mathrm{~mL} / \mathrm{kg} / \mathrm{h}$ in group 1 versus $1.13 \mathrm{~mL} / \mathrm{kg} / \mathrm{h}$ in group 2 (Wilcoxon's rank sum, $P=.03$, Fig 2B).

\section{DISCUSSION}

Hemorrhage is the major complication in neonates during ECMO. Among all Extracorporeal Life Support Organization (ELSO) registry patients treated by ECMO hemorrhagic complications occurred in $21 \% .^{5}$ In $\mathrm{CDH}$ patients treated by ECMO the overall incidence of bleeding complications appears to be $43 \%$ (209 of 483) including a $24 \%$ (117 of 483 ) incidence of operative site bleeding. ${ }^{6}$ Repair of the hernia defect while on ECMO may increase the risk of bleeding complications up to $58 \%$ to $60 \% .{ }^{6,7}$ Our initial experience — reflected in group 1 of this study--is consistent with these reported rates: six of the first $10 \mathrm{CDH}$ patients treated by ECMO had severe hemorrhage (intracranial, 1; surgical site, 5). Hemorrhagic complications are a hallmark of poor outcome. ${ }^{7}$ A statistically significant difference in bleeding 

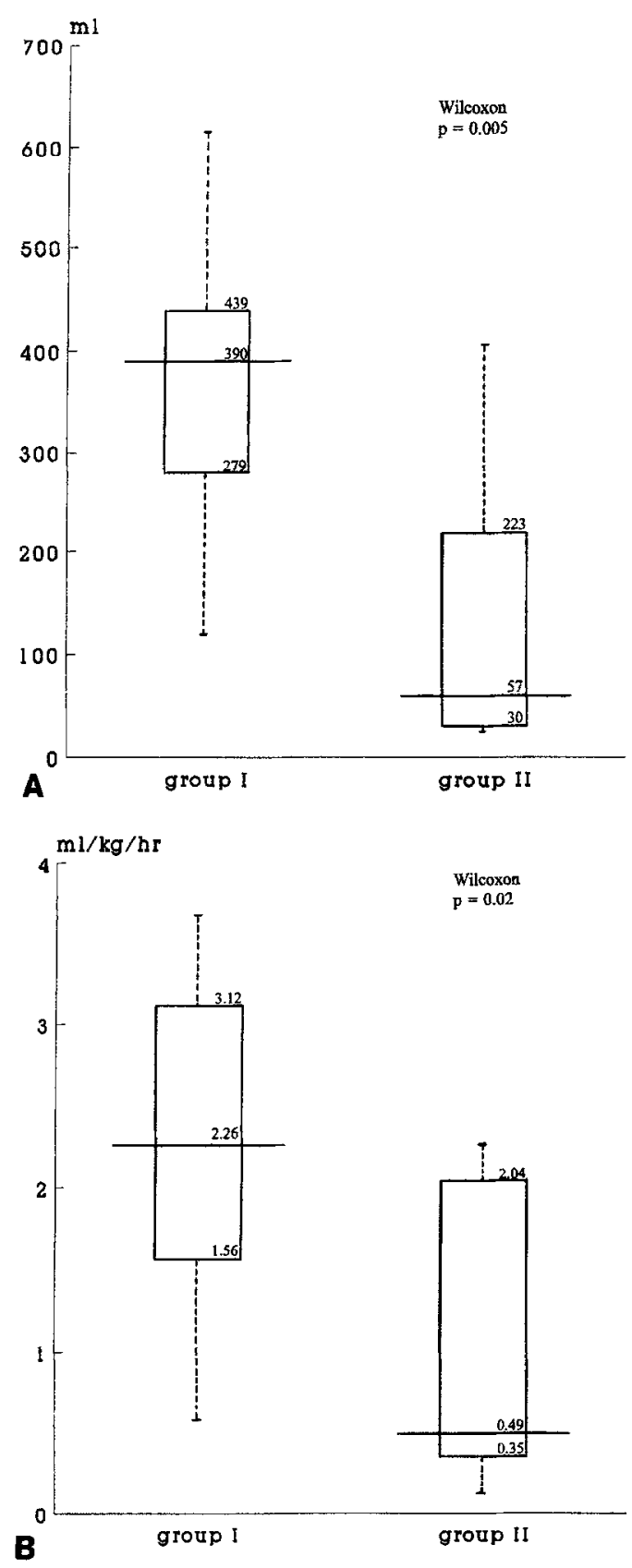

Fig 1. Box-plots of intra- and postoperative blood loss after $\mathrm{CDH}$ repair on ECMO in both groups (group 1 without the use of TEA, group 2 with TEA). They illustrate the distribution of data. The bottom and the top of the box indicate the first and third quartile, the line in between indicates the median, and the dotted lines represent the extreme values (range). (A) Total volume $(\mathrm{mL}$ ) and (B) volume per $\mathrm{kg}$ body weight per postoperative ECMO time $(\mathrm{mL} / \mathrm{kg} / \mathrm{h})$.

complications has been found between surviving and nonsurviving $\mathrm{CDH}$ patients who needed ECMO support. ${ }^{6,7}$ The reported incidence of fatal hemorrhage is $4 \%$ to $5 \%,{ }^{6,8}$ However, this rate is probably higher because any hemorrhagic complication may force the patient to be removed from ECMO earlier, and the immediate cause of death would be classified as pulmonary failure rather than hemorrhagic. ${ }^{6}$ We only can confirm this experience because all patients who died in this series had major hemorrhagic complications.

So far we repair CDH on ECMO late in the ECMO course when the patient had been shown to be weanable from ECMO. In this concept, a recurrence of persistent pulmonary hypertension of the newborn (PPHN), elicited by the surgical procedure and the conscquently diminished thoracic compliance, can be controlled by ECMO,
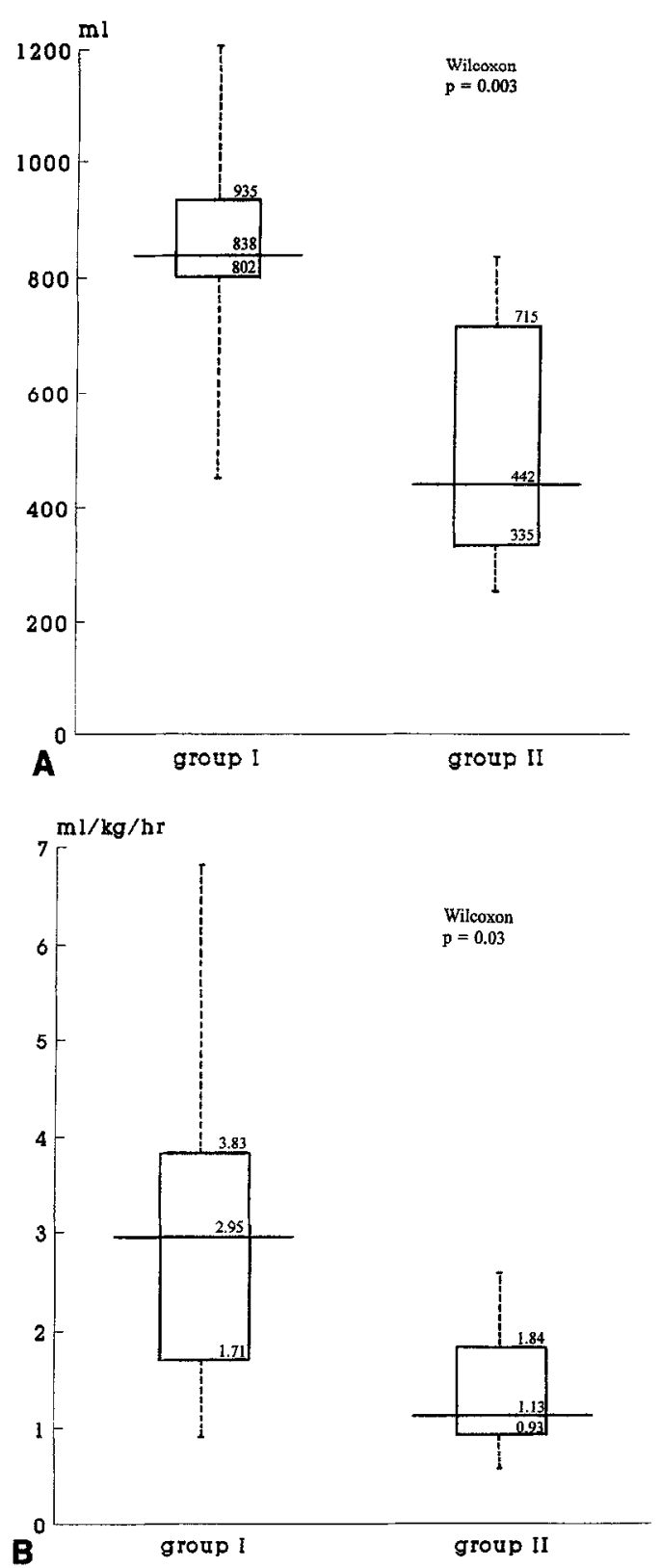

Fig 2. Box-plots of transfusion requirements of RBCs in CDH patients, treated without (group 1 ) and with TEA (group 2). They illustrate the distribution of data. The bottom and the top of the box indicate the first and third quartile, the line in between indicates the median and the dotted lines represent the extreme values (range). (A) Total volume during the whole ECMO run. (B) Volume per $\mathrm{kg}$ body weight per postoperative ECMO hour $(\mathrm{mL} / \mathbf{k g} / \mathrm{h})$. 
Table 1. Demographic Data

\begin{tabular}{|c|c|c|c|}
\hline & $\begin{array}{l}\text { Group } 1 \\
(n=9)\end{array}$ & $\begin{array}{l}\text { Group } 2 \\
(n=10)\end{array}$ & $\begin{array}{c}\text { Wilcoxorı's Rarik Sum } \\
P\end{array}$ \\
\hline Birth weight (g) & $\begin{array}{c}3,200 \\
(2,880,3,660)\end{array}$ & $\begin{array}{c}3,050 \\
(2,700,4,050)\end{array}$ & .96 \\
\hline Age at ECMO (h) & $\begin{array}{c}25 \\
(18,27)\end{array}$ & $\begin{array}{c}18 \\
(16,28)\end{array}$ & .68 \\
\hline Duration of ECMO (h) & $\begin{array}{c}181 \\
(150,217)\end{array}$ & $\begin{array}{c}130 \\
(110,167)\end{array}$ & .02 \\
\hline Time of $\mathrm{CDH}$ repair (ECMO h) & $\begin{array}{c}108 \\
\{87,143\}\end{array}$ & $\begin{array}{c}92 \\
(67.110)\end{array}$ & .15 \\
\hline
\end{tabular}

NOTE. The median values are stated with the $25 \%$ and $75 \%$ percentiles for all variables.

whereas ECMO could be withdrawn soon in case of hemorrhagic complications.

Adhering to our strategy, in which the benefits of perioperative ECMO support have to be outweighed by the risks of hemorrhagic complications, it seemed to be important to diminish the chance of those complications. Initially it was thought that bleeding complications during ECMO were caused by the anticoagulation. Undoubtedly heparinization is an important, but certainly not the only, factor in the occurrence of hemorrhage. It is known from the cardiopulmonary bypass (CPB) surgery, that fibrinolysis is a cause of postoperative bleeding and that the fibrinolytic activity increased immediately after CPB had begun and remained elevated throughout the period of extracorporeal circulation (ECC). ${ }^{9}$ So, the increased fibrinolytic activity seems to be caused by ECC itself. ${ }^{9}$ Fibrinolysis is believed to play a role in the increased hemorrhagic tendency in patients who require extracorporeal life support (ECLS) as well. ${ }^{10,11}$

The increased fibrinolysis during $\mathrm{ECC}$ and ECLS is possibly caused by an imbalance between tissue plasminogen activator (TPA) and plasminogen activator inhibitor (PAI); two of the major components regulating fibrinolysis $^{1 !}$ (Fig 3). McVeen et al $^{10}$ found a marked elevation of both PAI activity and TPA antigen in pre-ECMO infants experiencing respiratory distress. After institution of ECLS there is a rapid reduction of PAI activity within 24 hours, whereas TPA levels appear to remain more ele-

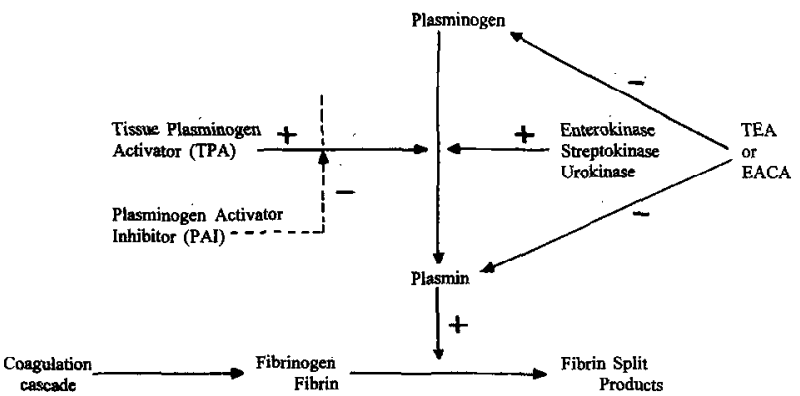

Fig 3. Schematic diagram of the fibrinolytic system. EACA and TEA inhibit fibrinolysis by binding to plasminogen and plasmin. Urokinase and TPA accelerate the formation of plasmin from plasminogen. vated and decline more gradually during ECMO treatment. ${ }^{10}$ This imbalance may cause an increased risk for hemorrhage. Therefore, antifibrinolytic therapy represents a pharmacological modality to reduce hemorrhagic complications on ECMO.

Drugs used to inhibit fibrinolysis during and after CPB surgery are epsilon-aminocaproic acid (EACA), TEA and aprotinine. ${ }^{12,13}$ EACA and TEA inhibit fibrinolysis by binding to the lysine binding sites of plasminogen and plasmin, which are the binding sites for fibrin (Fig 3). In this manner they blocked the fibrin breakdown by plasmin. The affinity of TEA for plasminogen is much stronger than EACA, so that TEA is 6 to 10 times as potent as EACA. ${ }^{13}$ Moreover TEA also competitively inhibits the activation of enterokinase. EACA has been adopted for use in neonatal ECLS patients by Wilson et al. ${ }^{3}$ Because EACA was not registered in the Netherlands, we choose TEA instead of EACA. Because the optimal dosage of TEA for neonates on ECMO is not known, we tried to determine the dosage and the means of administration on the basis of the report of Horrow et al ${ }^{13}$ about TEA. The recommended dosage by the manufacturer and the dosage of EACA used by Wilson (taking into consideration the greater efficacy of TEA) gave us guidelines for the dosing scheme. ${ }^{3,13}$

Patients who received TEA perioperatively had significantly less blood loss while on ECMO than the patients who did not receive. TEA (Wilcoxon's rank sum, $P=.005$ ). Similarly the transfusion requirements of RBC were significantly less in the TEA-treated group (Wilcoxon's rank sum, $P=.003$ ). No patients in the TEA-treated group had to be withdrawn early from ECMO support because of major bleeding. The survival rate for group 2 was much higher (100\% v 56\%). The improved survival in group 2 may be attributed to the decreased occurrence of severe hemorrhages.

Those data may reflect the possibility that antifibrinolytic therapy has played a role in the diminution of bleeding complications and the improved survival. However, these results may be attributed as well to the increased experience of the whole ECMO team. Because this is an unblinded study with historical controls, it is 
more difficult to unravel the influence of the gained experience on the one hand and the influence of TEA on the other hand on the improved results. It can be supposed that less blood loss and less RBC requirement can be explained by a better and more well-balanced anticoagulation management in the second group as a result of learning over time.

To investigate the effect of the learning curve, the RBC requirements were studied in all other ECMO patients (CDH excepted) in the same time frames as group 1 and 2 CDH patients were treated. In the first episode (1991 to 1992) the median $\mathrm{RBC}$ requirement during $\mathrm{ECMO}$ was $0.66 \mathrm{~mL} / \mathrm{kg} / \mathrm{h}$ of ECMO versus $0.75 \mathrm{~mL} / \mathrm{kg} / \mathrm{h}$ in the second episode (1993 to $1995, P=0.27$ ). This observa tion does not suggest a big alteration in ECMO handling caused by the learning curve.

With respect to the operative technique there was no fundamental change in the surgical approach with the advent of ECMO. This technique has been rooted in a morc than 20-ycar surgical experience with $\mathrm{CDH}$ repair. So it is hard to believe that a learning curve or a big alteration in the operative procedure is responsible for the bleeding complications in the early part of this study (group $1 \mathrm{CDH}$ patients).

Although the validity of this study may be a point of debate because of the use of historical controls, the following points can be made: (1) The preoperative RBC requirements in $\mathrm{CDH}$ paticnts on $\mathrm{ECMO}$ in both episodes $(0.83 \mathrm{~mL} / \mathrm{kg} / \mathrm{h}$ in group 1 and $0.96 \mathrm{~mL} / \mathrm{kg} / \mathrm{h}$ in group 2) were comparable to the $\mathrm{RBC}$ requirements in all other indications in both episodes $(0.66 \mathrm{~mL} / \mathrm{kg} / \mathrm{h}$ and 0.75 $\mathrm{mL} / \mathrm{kg} / \mathrm{h}$, respectively). (2) The postoperative $\mathrm{RBC}$ requirements after $\mathrm{CDH}$ repair on ECMO in the second episode (group 2, $1.13 \mathrm{~mL} / \mathrm{kg} / \mathrm{h}$ ) werc comparable to the $\mathrm{RBC}$ requirements in the pre-CDH repair episodes $(0.83$ to $0.96 \mathrm{~mL} / \mathrm{kg} / \mathrm{h})$ and in all other ECMO indications $(0.66$ to $0.75 \mathrm{~mL} / \mathrm{kg} / \mathrm{h}$ ). (3) The postoperative $\mathrm{RBC}$ requirements after $\mathrm{CDH}$ repair on ECMO in the first period (group 1 without the use of TEA, $2.96 \mathrm{~mL} / \mathrm{kg} / \mathrm{h}$ ) differed significantly from the requirements in the second period (group 2 with the use of TEA, $1.13 \mathrm{~mL} / \mathrm{kg} / \mathrm{h})(P=.03)$. (4) The surgical procedure was well established over years and did not change with the introduction of ECMO or during the study period. Therefore it may be concluded that TE $\Lambda$ is effective in controlling bleeding complications and in reducing $\mathrm{RBC}$ transfusion requirements.

$\Lambda$ though thrombotic complications are to be expected with the use of TEA, the reports concerning antifibrinolytic therapy during and after CPB surgery did not show an increase in those complications. ${ }^{12,13}$ In this study rather severe thrombotic complications were encountered in the first two patients treated with TEA. Right atrial and superior caval vein (SCV) thrombosis developed with an SCV syndrome and a long-lasting chylothorax. It was unclear whether these complications of central venous line thrombosis several days after ECMO were caused by TEA because we experienced the similar complications previously in two patients of group 1 who did not receive TEA. In addition those complications have becn reported as well after ECMO without the use of antifibrinolytic therapy, ${ }^{14,15}$ and thrombosis around an indwelling central venous line is a fairly known complication in neonates. ${ }^{16}$ However, meeting these problems and noting fatal thrombotic complications by the use of antifibrinolytic therapy, ${ }^{17}$ we decided to adapt the dosage and the administration of TEA. Since that alteration, neither severe hemorrhages nor severe thrombotic complications were observed.

This study demonstrates that TEA is effective in reducing postopcrative blood loss and hemorrhagic complications associated with $\mathrm{CDH}$ repair on ECMO. It also reflects the possibility that TEA may be responsible for severe thrombotic complications. Empirically, based on our experience, the appropriate dosage and administration pattern of TEA for $\mathrm{CDH}$ repair during ECMO seem to be one bolus of $4 \mathrm{mg} / \mathrm{kg}$ TEA intravenously 30 minutes before the anticipated $\mathrm{CDH}$ repair and a continuous infusion of $1 \mathrm{mg} / \mathrm{kg} / \mathrm{h}$ TEA during the 24 hours after $\mathrm{CDH}$ repair.

\section{REFERENCES}

1. vd Staak FHJM, de Haan AFJ, Geven WB, et al: Improving survival for patients with high-risk congenital diaphragmatic hernia by using extracorporeal membrane oxygenation. J Pediatr Surg 30:14631467,1995

2. vd Staak $F$, Geven W, Oeseburg B, et al: Experience with delayed repair of congenital diaphragmatic hernia during extracorporeal membrane oxygenation in an European Center. Pediatr Surg Int 8:187-190, 1993

3. Wilson JM, Bower LK, Fackler JC, et al: Aminocaproic acid decreases the incidence of intracranial hemorrhage and othcr hemorrhagic complications of ECMO. J Pediatr Surg 28:536-541, 1993

4. Bartlett RH, Gazzaniga AB, Toomasian J, et al: Extracorporeal membrane oxygenation (ECMO) in neonatal respiratory failure: 100 Cases. Ann Surg 204:236-245, 1986
5. Stolar CJH; Snedecor SM, Bartlett RH: Extracorporeal membrane oxygenation and neonatal respiratory failure: Experience from the Extracorporeal Life Support Organization. J Pediatr Surg 26:563-571, 1991

6. Varquer. WD, Cheu HW: Hemorrhagic complications and repair of congenital diaphragmatic hernias: Does timing of the repair make a difference? Data from the Extracorporeal Life Support Organization. J Pediatr Surg 29:1002-1006, 1994

7. Lally KP, Paranka MS, Roden J et al: Congenital diaphragmatic hernia: Stabilization and repair on ECMO. Ann Surg 216:569-573, 1992

8. Price MR, Galantowicz ME, Stolar CJH: Congenital diaphragmatic hernia, extracorporeal membrane oxygenation and death: A spectrum of etiologies. J Pediatr Surg 26:1023-1027, 1991

9. Kucuk O, Kwaan HC, Frederickson J, et al: Increased fibrinolytic 
activity in patients undergoing cardiopulmonary bypass operation. Am J Hematol 23:223-229, 1986

10. McVeen RV, Lorch V, Carroll RC, et al: Changes in fibrinolytic factors in newborns during extracorporeal membrane oxygenation (ECMO). Am J Heinatol 38:254-255, 1991

11. Giuliani R, Szwarcer E, Aquino EM, et al: Fibrin-dependent fibrinolytic activity during extracorporeal circulation. Thromb Res 61:369-373, 1991

12. Karski JM, Teasdale SJ, Normal PH, et al: Prevention of postbypass bleeding with tranexamic acid and $\epsilon$-aminocaproic acid. $\mathrm{J}$ Cardiothor Vasc Anesth 7:431-435, 1993

13. Horrow JC, Hlavacek J, Strong MD, et al: Prophylactic tranexamic acid decreases bleeding after cardiac operations. J Thorac Cardiovasc Surg 99:70-74, 1990
14. Zreik H, Resai Bengur A, Meliones JN, et al: Superior vena cava obstruction after extracorporeal membrane oxygenation. J Pediatr 127:314-316, 1995

15. Marsh D, Wilkerson S, Cook I, et al: Right atrial thrombosis in neonates receiving central venous lines after extracorporeal membrane oxygenation. Crit Care Med 16:202-203, 1988

16. Wever MLG, Liem KD, Geven WB, et al: Urokinase therapy in neonates with catheter related central venous thrombosis. Thromb Haemost 73:180-185, 1995

17. Hocker JR, Saving KL: Fatal aortic thrombosis in a neonate during infusion of epsilon-aminocaproic acid. J Pediatr Surg 30:14901492,1995 